\title{
The Primex Proposal, Minimum Bid Price Requirements, And NASDAQ Market Woes
}

Ted Azarmi, California State University, Long Beach

SungSup (Brian) Choi, Columbia University, New York

Christine Haecker, Universitaet Tuebingen, Germany

\begin{abstract}
The objective of this case is to teach and initiate a class discussion about the Primex proposal and minimum bid price requirements at NASDAQ. The discussion is facilitated by a real world case example that focuses on current NASDAQ market woes. Issues central to the performance of NASDAQ as a market place are analyzed. In addition, this study considers the effect of the merger of Instinet and Island on NASDAQ and evaluates NASDAQ's IPO decision.
\end{abstract}

\section{Discussion}

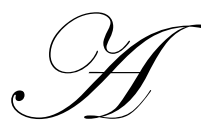

7:00pm on March 11, 2003, James Smith began his discussion as the chairperson of an introductory meeting of the market consultants group (MCG) by stating: "We have seen a commoditization of products and services in computer hardware and telecommunications. Margins have become paperthin and there is almost no brand equity. The products have become similar to lumber or steel, so that firms cannot expect to benefit from an economic rent associated with their brand reputation. In addition, we have experienced a dotcom bubble that contributed to the NASDAQ's climb up to 5,000 points three years ago and its subsequent decline to 1,271 points at today's market closing."

Janet Jones, the most senior consultant in the group, cut in with a comment in support of James' statements: "Yeah, NASDAQ is dominated by firms in the technology and telecommunication-sector. James' analysis of these sectors enables us to get a grasp of current NASDAQ woes." James agreed and added: "the performance of NASDAQ as a market place is affected by the same economic factors that affect other markets. Therefore, we should also focus our discussion on the general direction of the stock market as a whole and the US economy. The US stock market recently has been affected adversely by bad news related to war, terrorism, low corporate earnings, accounting irregularities, job losses, and the economic downturn."

Adam Macintosh, a new IPO specialist in the group, joined the discussion by adding that NASDAQ's performance disproportionately depended on the IPO market. The outlook for IPOs was worse than it had been for at least a decade. Very few IPOs had been undertaken in 2002, with the number of IPOs dropping further from an already low level in 2001. There had been only three major IPOs so far this year, raising about $\$ 500$ million. In contrast, there were 16 initial public offerings on NASDAQ during the fourth quarter of 2002 compared with 24 IPOs in the fourth quarter of 2001. Most IPOs this year were delayed for lack of interest, had to cut prices, and showed significant price losses in the IPO after-market.

Vivian Carter, who had joined the group after a long tenure at SEC, craftily switched the discussion to market regulation. She said that some investment professionals wonder about the adverse impact of the dropping of the $\$ 1$ trading minimum rule on stockholders, listed companies, and NASDAQ itself. Vivian, who has also received an MBA from Harvard Business School, stated that from a purely theoretical and academic point of view on the above regulatory issue, there should be no impact from the dropping of the $\$ 1$ rule. In her mind there was no theoretical basis for stockholders, listed companies, or the NASDAQ market to have a preference for stock prices to be trading above one dollar or in a range of $\$ 1$ to $\$ 100$ (for example): "Valuations should be the same, if a company has 100,000,000 shares worth one dollar each or 1,000,000 shares valued at $\$ 100$ each. All that should matter is the 
net present value of the future cash flows that are derived from growth opportunities that a firm offers. However, both psychological and practical reasons deter investors from trading and investing in stocks that are under-a-dollar or penny stocks. The psychological reason for that is that these stocks have the stink of death about them. Investors feel that penny stocks are issued by firms that cannot keep their valuation at a reasonable per share price of above one dollar." Practically, she added, this would make sense in a market where most firms target their shares to be valued well over $\$ 1$ and not much over $\$ 100$. Then, if a firm's share price was to fall under $\$ 1$, one could infer that the firm had failed; that its inability in keeping its value within the expected range implied that it did not have future opportunities for growth. Correspondingly, Vivian argued that a stock split would convey good news in a world where firms keep their stock prices in a range of $\$ 1$ to $\$ 100$. It would imply that the firm is expecting its valuation to remain much above $\$ 100$ and definitely higher than $\$ 1$ dollar after a split. This argument would also depend on investors' inferring that management or insiders were signaling unexpected "good news" with the split decision.

Vivian added that another practical aspect of penny stocks is that they are obscure and known through a listing called the pink sheet. Fewer people obtain stock information and follow share price developments. Hence these stocks would be more volatile, less liquid, and therefore risky. If NASDAQ was to acquire the reputation of being a market that trades a lot in penny stocks, main stream investors and fiduciaries obligated to prudent investment decisions may stay away from it. She provided the example of a trustee managing the savings of orphans and widows who has to attest to a court of law that the investments were made in a prudent manner. In this case, the reputation of NASDAQ as a market place matters would matter greatly to this investor. Thus, she concluded, the reputation of a market with a significant number of stocks under $\$ 1$ listed may be tarnished in certain circles.

At this point everyone was listening attentively to Vivian's long digression into regulatory issues. Realizing the importance of this line of analysis, James asked Vivian if there was any other rule that NASDAQ was thinking about dropping or relaxing. Vivian responded that indeed there was. On January 29 of 2003 a related rule change was under discussion. NASDAQ proposed a measure that would provide an option to listed firms that meet higher financial requirements to take an extended compliance period to satisfy minimum bid price requirements. Paging through the documents in her folder and pausing on one page, Vivian Carter added that the exact proposal was as follows (See Nasdaq homepage):

1. Extend the bid price grace period for all National Market issuers from 90 calendar days to 180 calendar days, and provide an additional 180 calendar day grace period for those National Market issuers able to demonstrate compliance with the core National Market initial listing criteria.

2. Maintain the initial 180-calendar day bid price grace period for all Small Cap issuers, but extend the bid price grace period for Small Cap issuers demonstrating compliance with the core Small-Cap initial listing criteria from 180 to up to 540 days (approximately 18 months). Compliance with this standard will be verified every 180 days.

3. Extend the pilot program expiration from December 31, 2003 to December 31, 2004.

While handing the paper to the person sitting next to her, Vivian added that there also was the Primex proposal: "It is an innovation that seeks to bring some aspects of an auction market mechanism to NASDAQ's dealer-focused trading platform. This may provide investors with an opportunity to receive improved prices over the bids and offers displayed by the dealers. However, NASDAQ has to walk a fine line between dealers' interests and those of investors, to ensure that the Primex Auction System succeeds."

Vivian then discussed one successful rule change in the recent past: "In April 2001, NASDAQ moved to decimal pricing. This benefited investors by decreasing spreads to a reported $50 \%$, or to a weighted-average of a 4 cents spread for NASDAQ traded stocks. Generally, this rule change had a positive impact, although it did contribute to some negative reactions by some dealers." 
James felt that the regulation discussion was getting the meeting a bit off track from its focus. He asked the question that he considered most crucial: "Does the NASDAQ management have the right priorities and has it made the right moves?"

Walter Hess, a marketing specialist on the committee addressed James' question. He stated that NASDAQ is a huge market, the world's largest electronic stock market with approximately 3,700 companies. It lists and trades more shares per day than any other market in US. He reasoned that due to its large volume NASDAQ has to focus on prioritizing service and on keeping its relatively large number of dealers satisfied. It got to have a focus on dealers and their interests. Walter believes that another key ingredient to NASDAQ's success in the past has been its ability to attract leaders in certain high growth industries such as technology and communications. It has done so by being an important capital formation device for these firms early on. Both of these priorities are relevant for the future, too. However, he realizes that the tricky issue is to identify other sectors that have the potential to grow in the next decade the way the technology and telecommunication firms have grown during the 1990's. Those right moves are extremely difficult to identify now.

Adam Macintosh added that one should also focus on NASDAQ's plans of an IPO. He reminded everyone of his earlier comments on the current poor IPO market. He stated that in his opinion negative investor sentiment is mirrored by price cuts, delays, and market losses in initial trading. Aside from the negative IPO market conditions, Adam assessed NASDAQ's plan to become a publicly traded company as vulnerable. In the current bear market, NASDAQ is facing strong pressure on all its sources of revenue. Yesterday (on Monday March 10), NASDAQ reported a fourth-quarter loss of three cents per share, compared with a loss of 12 cents per share in the year-ago quarter. Revenue fell to $\$ 183.6$ million from \$215.5 million. Increased competition and shifts in market composition placed additional pressure on revenue throughout the year of 2002, as firms executed transactions and reported trades in NASDAQ-listed securities outside of NASDAQ's systems. Adam strongly emphasized that, for a successful IPO, NASDAQ has to prove that it's a viable investment.

Walter cut in stating that we should also consider the effect of the merger of Instinet and Island on NASDAQ's SuperMontage. He believes that a merger of the two biggest Electronic Communications Networks (ECNs), Instinet Group and Island ECN, would combine Instinet's appeal to big institutions, Island's core of active traders, and their $30.4 \%$ share of NASDAQ trading. Walter also stated that Chicago-based Archipelago LLC was taking another course: its system now handles trading at San Francisco's Pacific Exchange, allowing it to execute orders without going through NASDAQ. Besides diverting trades from SuperMontage, both Archipelago and the Instinet-Island combination plan to squeeze NASDAQ by reporting their trades on other exchanges, thus claiming the revenue that NASDAQ otherwise would receive from reselling quote and trade data to brokers and investors.

According to a study by Putnam Lowell, Instinet/Island accounted for 30\% of NASDAQ trading volume in February 2003; Archipelago for 14\%; and SuperMontage for a mere 20\%. NASDAQ will have to develop a plan of action to win back market share. Analysts believe that one way to do that might be the acquisition of Archipelago. Walter stated that NASDAQ seemed to be considering this strategic move at the moment.

Next, Rita Avon, a management strategy specialist, brought up NASDAQ's global strategy, in particular NASDAQ's move to shut down its Japanese operations. She stresses that she was pessimistic about the Japanese stock market. In her opinion, shutting down NASDAQ Japan was the right move. NASDAQ needed to cut its losses and get out. She evaluates Japan as having fundamental inefficiencies in its labor and capital markets, banking problems, and a lack of solid corporate and governmental leadership, thereby making the Japanese stock market unattractive for the foreseeable future.

Regarding other global plans, Rita discussed NASDAQ's new trading platform called SuperMontage. This technology was considered as being one generation ahead of NASDAQ's old trading platform. She added that there were plans to role this new platform out for trading in Europe, Asia, and perhaps in other regions in the future.

Rita said that we should also pay attention to the quality of management talent, and in particular to NASDAQ chairman Mr. Harwick's abilities. She stated that she has no reason not to have confidence in his 
leadership. You could second-guess a few of his decisions, however hindsight is twenty-twenty. Most of NASDAQ's current problems may be traced back to the burst of the Dotcom bubble, as well as the commoditization of hardware computer business and much of telecommunication products. These problems affected the sectors that were leading stocks in NASDAQ market. In addition, she commented that this market was suffering together with Dow-components and NYSE traded shares with the downturn in US economy.

Finally, James Smith concluded the meeting with the following remarks: "Survival of this market is not an issue now. Its survival will only become an issue if it begins to lose its dealers or investors. That can only happen if these participants, particularly the dealers, reach a point where they have a financial interest to participate in an alternative market (provided that there is a choice). However, for NASDAQ to go up to anywhere close to 5000 and repeat its past great success, it needs to develop the ability to attract small firms that will become the Microsoft's of the next decade, i.e. the leaders that will define an entire sector."

Satisfied with today's meeting, James proposed that the agenda for the next meeting be the analysis of the Primex proposal and the finalization of the current discussion as a complete and detailed report on analyzing the NASDAQ market.

\section{Case Analysis}

Prepare a general analysis of the Primex proposal. Focus on providing a complete and detailed report on analyzing the NASDAQ market from all viewpoints (regulation issues that may help Vivian, IPO related issues, NASDAQ management issues, etc.) and for each of the above participants.

\section{Case Questions}

1. What are the reasons for the current problems at NASDAQ?

2. The case compares the IPO data for the first quarter of 2003 to data of the fourth quarter of 2002 and 2001. Is this an appropriate benchmark? If not, what would be a more meaningful benchmark?

3. What impact would dropping the minimum bid price requirement of one dollar have on the stockholders, companies, and NASDAQ itself?

4. Is there any other rule NASDAQ is thinking about dropping or relaxing?

5. Has NASDAQ got its priorities right and has it made the right moves?

6. Discuss NASDAQ's plans of an IPO and analyze the effects of an IPO on all stakeholders. (Hint: draw on going public experiences of CBOT).

7. What would be the effect of the merger of Instinet and Island on NASDAQ's Supermontage?

8. Comment on the NASDAQ's global plans and moves like shutting down NASDAQ-Japan?

9. How far is the NASDAQ chairman Mr. Harwick responsible for NASDAQ's woes?

10. What is the future of NASDAQ and are there ways of improving it?

\section{References}

Azarmi Ted, Haecker Christine (2003): "NASDAQ Woes”, Chartered Financial Analyst Journal, June. 